\title{
Knowledge, attitudes and practice of clinicians managing chronic pain in a tertiary care facility
}

\begin{tabular}{|c|c|}
\hline \multicolumn{2}{|c|}{$\begin{array}{l}\text { Authors: } \\
\text { Solomon Rop }{ }^{1} \text { (D) } \\
\text { Joseph M. Matheri }{ }^{1} \text { (D) } \\
\text { Nassib Tawa }{ }^{1,2} \text { (D) }\end{array}$} \\
\hline \multicolumn{2}{|c|}{$\begin{array}{l}\text { Affiliations: } \\
{ }^{1} \text { Department of } \\
\text { Rehabilitation Science, } \\
\text { College of Health Sciences, } \\
\text { Jomo Kenyatta University of } \\
\text { Agriculture and Technology, } \\
\text { Nairobi, Kenya }\end{array}$} \\
\hline \multicolumn{2}{|c|}{$\begin{array}{l}{ }^{2} \text { Division of Physiotherapy, } \\
\text { Faculty of Medicine and } \\
\text { Health Sciences, Stellenbosch } \\
\text { University, Cape Town, } \\
\text { South Africa }\end{array}$} \\
\hline \multicolumn{2}{|c|}{$\begin{array}{l}\text { Corresponding author: } \\
\text { Solomon Rop, } \\
\text { ropsolopt@gmail.com }\end{array}$} \\
\hline \multicolumn{2}{|c|}{$\begin{array}{l}\text { Dates: } \\
\text { Received: } 29 \text { June } 2021 \\
\text { Accepted: } 13 \text { Oct. } 2021 \\
\text { Published: } 31 \text { Jan. } 2022\end{array}$} \\
\hline \multicolumn{2}{|c|}{$\begin{array}{l}\text { How to cite this article: } \\
\text { Rop, S., Matheri, J.M. \& } \\
\text { Tawa, N., 2022, 'Knowledge, } \\
\text { attitudes and practice of } \\
\text { clinicians managing chronic } \\
\text { pain in a tertiary care facility', } \\
\text { South African Journal of } \\
\text { Physiotherapy 78(1), a1597. } \\
\text { https://doi.org/10.4102/sajp. } \\
\text { v78i1.1597 }\end{array}$} \\
\hline \multicolumn{2}{|c|}{$\begin{array}{l}\text { Copyright: } \\
\text { (C) 2022. The Authors } \\
\text { Licensee: AOSIS. This } \\
\text { is licensed under the } \\
\text { Creative Commons } \\
\text { Attribution License. }\end{array}$} \\
\hline \multicolumn{2}{|l|}{ Read online: } \\
\hline 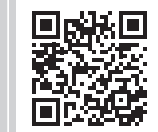 & $\begin{array}{l}\text { Scan this QR } \\
\text { code with your } \\
\text { smart phone or } \\
\text { mobile device } \\
\text { to read online. }\end{array}$ \\
\hline
\end{tabular}

Background: Chronic pain is a common clinical symptom and has a high socio-economic and health burden on patients, clinicians and the healthcare sector. Globally, clinicians continue to exhibit limited knowledge, negative attitudes and misconceptions about chronic pain, raising public health concerns.

Objective: Our study aimed to determine the level of knowledge, attitudes and practices of clinicians towards assessment and management of patients with chronic pain in a tertiary hospital.

Methods: This cross-sectional study at a tertiary care hospital in Kenya adopted a census method to recruit participants $(n=240)$. A questionnaire containing 77 items derived from the Revised Pain Knowledge and Attitudes Questionnaire (RPKAQ) and the Knowledge and Attitudes Survey regarding Pain (KASRP) was used to collect data. The questionnaire had three parts. Part A had six items to determine information on demographic characteristics. Part $\mathrm{B}$ and $\mathrm{C}$ had 54 and 23 items, respectively, that determined information on knowledge, attitudes and practice of clinicians managing chronic pain. Data were analysed using SPSS Version 24.

Results: Response rate was 83.3\% ( $n=153)$. Only 9\% $(n=14)$ of the respondents were believed to have adequate knowledge and positive attitudes; $62 \%(n=95)$ used best practice for cognitive/behavioural management of chronic pain. Few $(9 \% n=14)$ used best practice in the assessment and measurement of chronic pain.

Conclusion: There is inadequate knowledge, attitudes and practices amongst clinicians regarding assessment and management of chronic pain. Future research is needed in a wider population to compare these results.

Clinical implication: It may motivate clinicians to improve their level of knowledge, attitudes and practices for pain management, hence improving poor chronic pain outcome.

Keywords: chronic pain; knowledge; attitudes and practices; pain; pain management; assessment; clinician.

\section{Background}

Despite the recent advances in understanding the algorithm of diagnosing and treating clinical pain, many clinicians globally continue to exhibit limited knowledge, negative attitudes and misconceptions about chronic pain, raising public health concerns (Al-Quliti \& Alamri 2015; Clenzos, Naidoo \& Parker 2016; Magalhães et al. 2012; Nuseir, Kassab \& Almomani 2016; Ung et al. 2016). Chronic pain is a common clinical symptom reported by patients in referral facilities and has a significantly high socio-economic and health burden on patients, clinicians and the healthcare sector (Goldberg \& McGee 2011). Pain is defined as 'an unpleasant sensory and emotional experience associated with actual or potential damage of tissue' (International Association for the Study of Pain 2015). Regarding the relationship between chronic pain and tissue damage, 'the pain does not provide a measure of state of the tissue as it is modulated by many factors, which include somatic, psychological and social factors'. Therefore, 'the relationship between pain and tissue becomes less predictable as pain persists' (Moseley 2008). According to the International Association for the Study of Pain, Treede et al. (2018) and Raja et al. (2020) views are that the 'sensory and emotional aspect of chronic pain are thought to be without real biological cause and persist beyond the normal time for tissue healing'.

Patients suffering from chronic pain often report increasing levels of pain, activity limitation, participation restrictions and poor quality of life, which comes with high medical costs as a 
result of prolonged utilisation of healthcare services (Salazar, Mico \& Failde 2016). In practice, the outcomes of patients with chronic pain are often poor because of inaccuracy amongst clinicians in choosing and administering appropriate treatment (Kheshti et al. 2016). According to Breivik et al. (2006) and Nuseir et al. (2016) inaccurate prescription for patients with chronic pain may be a function of misclassification or misdiagnosis, which leads to inappropriate treatment and undesirable outcomes and increased health and social costs. Whereas the goal when managing people suffering from chronic pain is to relieve pain and improve function, a bio-psychosocial approach is currently preferred for improved outcome especially when provided by a multidisciplinary team (Bevers, Watts \& Gatchel 2016; Ernstzen, Louw \& Hillier 2017; Espejo-Tort et al. 2011; Moseley 2008). However, research evidence has shown that most clinicians utilise a biomedical approach, which is regarded as a retrogressive practice that is often associated with poor outcomes, reduced quality of life, increasing disability and the high cost of healthcare (Bevers et al. 2016; Espejo-Tort et al. 2011). According to Gustafsson and Borglin, (2013) improving clinicians' level of knowledge positively influences their attitudes and practice for effective management of patients with chronic pain. However, most of the studies with these outcomes were conducted in developed countries such as in the United Kingdom (Ryan et al. 2010), United States of America (Duke et al. 2013) and Asia (Al-Quliti \& Alamri 2015). In the African region, information regarding knowledge, attitudes and practices of healthcare professionals about assessment and management of patients with chronic pain is scanty. To address this gap, our study aimed to determine the level of knowledge, attitudes and clinical practices on assessment and management of chronic pain amongst clinicians in a tertiary care facility in Kenya. Our study's findings form an essential baseline for further research and inform future review of healthcare policy, capacity development programmes and practice.

\section{Method}

Our cross-sectional survey was conducted at Tenwek Hospital in Kenya from January 2020 to May 2020. We targeted the 240 different healthcare professionals who are directly involved in caring for patients within the hospital (as illustrated in Table 1).

We adopted a census method of sampling because of the small study population $(n=240)$. Although this method is

TABLE 1: Study population $(n=240)$

\begin{tabular}{lc}
\hline Professional & Number \\
\hline Medical officers, residents and specialists & 50 \\
Nurses & 124 \\
Clinical officers (physicians' assistants) & 40 \\
Anaesthetists & 15 \\
Physiotherapists & 4 \\
Oncology team & 7 \\
\hline Total & $\mathbf{2 4 0}$ \\
\hline
\end{tabular}

expensive and time-consuming it has no sampling error commonly seen in probability sampling methods and gives precise results. In addition, the census method is best used for heterogeneous populations (Ajay \& Micah 2014). Clinicians were included if they were directly caring for patients with chronic pain and were willing to participate and voluntarily gave signed consent.

\section{Data collection tool}

The revised Pain Knowledge and Attitude Questionnaire (RPKAQ) and a section adopted from the Knowledge and Attitudes Survey regarding Pain (KASRP) questionnaire, which mainly focuses on pharmacological management of pain was used to collect data. Both the RPKAQ and KASRP questionnaires have undergone cognitive testing and validation in different settings and cultures and have been found to be reliable (Cronbach's alpha of 0.65 and 0.80 , respectively); (Clenzos et al. 2016; Ferrell \& McCaffery 2012). The RPKAQ was designed to measure wide knowledge, attitudes and practices appropriate for clinicians, which includes the physiological basis of pain, psychological factors of pain perception, the developmental changes, the assessment and measurements of pain and cognitive and behavioural methods of pain management and pharmacological management of chronic pain. Each item was scored and the total ranges from $0 \%$ to $100 \%$. A score of $75 \%$ and above represents acceptability and it means the participant has adequate knowledge, attitudes and practices whilst those who score below $75 \%$ are considered to have inadequate knowledge, negative attitudes and poor practices towards assessment and management of patients with chronic pain.

\section{Procedure for data collection}

Prior to data collection, the first author sought permission to access clinicians from the hospital's human resource department. The clinicians who met the inclusion criteria were issued with an informed consent form. After signing and return of the consent form, the first author administered the study questionnaires for self-completion by each respondent.

\section{Data analysis}

Data were entered into a Microsoft Excel spreadsheet using predetermined data variables, which included age, gender, cadre, and years of practice, level of knowledge of chronic pain, professional practice and attitudes amongst others. Data were cleaned by cross-checking the entries for each variable in the Excel spreadsheet against our study questionnaires. The clean data Excel spreadsheet was transferred to SPSS software for processing and statistical analysis. Descriptive statistics in terms of means and standard deviation (SD) were calculated and presented in the form of summary tables and charts. 
TABLE 2: Socio-demographic characteristics of participants $(n=153)$.

\begin{tabular}{lcc}
\hline Characteristic & Frequency $(\boldsymbol{n})$ & Percentage (\%) \\
\hline Age group & 84 & 55 \\
$<30$ years & 47 & 30 \\
$31-40$ years & 19 & 13 \\
$41-50$ years & 3 & 2 \\
$>50$ years & & \\
Years of clinical practice & 108 & 71 \\
1-5 years & 27 & 17 \\
6-10 years & 18 & 12 \\
$>11$ years & & \\
Level of education & 106 & 70 \\
College diploma & 31 & 20 \\
Bachelor's degree & 8 & 5 \\
Master's degree & 8 & 5 \\
Post graduate degree & & \\
Clinician cadre & 77 & 50 \\
Nurses & 23 & 15 \\
Physicians' assistants & 34 & 21 \\
Medical officers, residents and specialists & 3 & 2 \\
Physiotherapist & 8 & 5 \\
Anaesthetist & 3 & 2 \\
Dentist & 5 & 3 \\
Oncology team & & \\
\hline
\end{tabular}

\section{Ethical considerations}

Ethical clearance was obtained from the National Commission for Science Technology and Innovation, Jomo Kenyatta University of Agriculture and Technology and Tenwek Hospital Ethical Review Committee (ERC). Participants were informed of their right to decline to participate and the process was purely voluntary. Confidentiality was maintained throughout the study and subsequent presentations. Consent from all potential participants was sought before questionnaires were administered. There were no names or identifiers linking questionnaires to respondent.

\section{Results}

A total of 153 clinicians took part in our study of whom 79 $(52 \%$;) were male and $74(48 \%)$ female. The majority 84 (55\%) were younger than 30 followed by $47(30 \%)$ who were aged between 31 and 40. Almost three quarters, 108 (71\%) of the participants had less than 5 years of clinical experience. Only $27(17 \%)$ had 6 years or more. The majority of participants $106(70 \%)$ had attained a college diploma, half 77 (50\%) of them were nurses and 23 (15\%) were physicians' assistants as illustrated in Table 2.

\section{Level of knowledge and attitudes on assessment and management of chronic pain}

The majority 139 (91\%) of the participants had inadequate knowledge and attitudes (they scored below 75\%) on assessment and management of chronic pain. Regarding their level of knowledge of the developmental changes in pain perception, few 48 (31\%) participants were knowledgeable. Very few 16 (10\%) participants had adequate knowledge and positive attitudes on the physiological basis of chronic pain management (see Table 3).
TABLE 3: Level of knowledge and attitudes on assessment and management of chronic pain $(n=153)$.

\begin{tabular}{|c|c|c|c|c|c|c|}
\hline \multirow[t]{2}{*}{ Variable } & \multicolumn{2}{|c|}{$\begin{array}{l}\text { Adequate } \\
\text { knowledge }\end{array}$} & \multicolumn{2}{|c|}{$\begin{array}{l}\text { Inadequate } \\
\text { knowledge }\end{array}$} & \multicolumn{2}{|c|}{$\begin{array}{l}\text { Average } \\
\text { score }\end{array}$} \\
\hline & $n$ & $\%$ & $n$ & $\%$ & SD & $\%$ \\
\hline \multicolumn{7}{|c|}{ Level of knowledge and attitudes on chronic pain } \\
\hline Physiological basis of pain & 16 & 10 & 137 & 90 & 12.6 & 61.7 \\
\hline Psychological factors of pain perception & 21 & 14 & 132 & 86 & 13.9 & 60.7 \\
\hline $\begin{array}{l}\text { Developmental changes in pain } \\
\text { perception }\end{array}$ & 48 & 31 & 105 & 69 & 18.9 & 64.2 \\
\hline \multicolumn{7}{|c|}{ Knowledge and attitudes on assessment and management } \\
\hline Assessment and measurement of pain & 14 & 9 & 139 & 91 & 15.9 & 51.7 \\
\hline $\begin{array}{l}\text { Cognitive/behavioural methods of pain } \\
\text { relief }\end{array}$ & 95 & 62 & 58 & 38 & 14.9 & 78.5 \\
\hline $\begin{array}{l}\text { Pharmacological management of } \\
\text { chronic pain }\end{array}$ & 11 & 7 & 142 & 93 & 11.8 & 54.5 \\
\hline Overall scores & 14 & 9 & 139 & 91 & 7.) & 61.9 \\
\hline
\end{tabular}

SD, standard deviation.

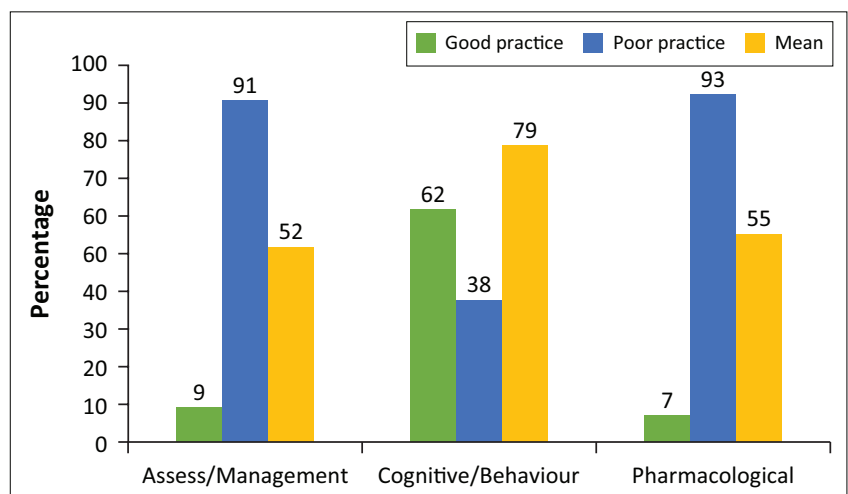

FIGURE 1: Current practice of assessment and measurement, cognitive/ behavioural and pharmacological intervention of chronic pain $(n=153)$.

\section{Current practice of assessment and measurement, cognitive/behavioural and pharmacological intervention of chronic pain}

For cognitive/behavioural intervention of chronic pain, the majority of the participants $(62 \% n=95)$ used best practice, with a mean score of 79\% (SD: $14.9 \%)$ whilst only $9 \%(n=$ $14)$ and $7 \%(n=11)$ of the participants used best practice in assessing and pharmacologically managing patients with chronic pain, respectively (see Figure 1).

\section{Discussion}

Our study is one of the few that has attempted to investigate the level of knowledge, attitudes and practices of clinicians managing chronic pain in a tertiary hospital in Kenya. Our results are a source of concern, as the majority of the participants had inadequate knowledge, negative attitudes and poor practices in managing chronic pain. These results are similar to studies that have also found clinicians who have inadequate knowledge, negative attitudes and poor practices regarding management of chronic pain (Al-Quliti \& Alamri 2015; Clenzos et al. 2016; Kheshti et al. 2016). Our findings may have been influenced by variations in participants' level and training programmes. As cited in other studies some clinicians may be inadequately prepared to assess and manage pain partly because of the form of training and clinical experiences (Kiwanuka \& Masaba 2018; 
Nuseir et al. 2016; Yaqoob \& Nasaif 2015). Furthermore, the majority of clinicians did not have much clinical experience $(71 \%, n=108)$, which is crucial to successfully manage chronic pain. This view is supported by Miró et al. (2019); Shipton et al. (2018); Enskär, Eaton and Harding (2007); Bouri et al. (2018) and Nuseir et al. (2016) who have shown that clinical experience and level of education influence clinician practice.

Although our study examined a wide range of clinical cadres, there was an uneven distribution amongst them; therefore, generalising our results to a larger population must be carried out cautiously because of the small study population and uneven distribution of clinical cadres. Despite this limitation, our results provide useful information on the selected care facility clinical cadre capacity for the assessment and management of clients with chronic pain and the need for the facility to generate an algorithm for chronic pain management to protect its clients' rights to quality care.

Few studies in the region are similar to our findings. A Kenyan study by Jin (2015) $(n=96)$, which evaluated 'the knowledge and attitudes of various healthcare workers regarding pain assessment and management in children' in the country's national referral hospital, found a significant knowledge gap amongst participants with over half (58.3\%) performing poorly, whilst an Ugandan study by Kizza et al. (2016) found that $73.5 \%$ of clinicians were perceived to have inadequate knowledge in key concepts of pain management. Furthermore, a South African study by Clenzos et al. (2016) found only $14.5 \%$ of participants with adequate knowledge. The results of our study contrasts with a comparative study in the United Kingdom, South Africa and Sweden $(n=106)$ amongst clinicians working with children with cancer by Enskär et al. (2007) who found that participants had high levels of knowledge and appropriate attitudes towards pain management.

We found few participants used best practice in the assessment and measurement of pain, which is similar to Clenzos et al. (2016) and Al-Quliti and Alamri (2015) who found $4 \% ;(n=8)$ and $5.7 \%(n=6)$ of participants, respectively, had adequate knowledge in this domain. Similarly, in the pharmacological domain, participants performed poorly, which corroborates the findings of Kheshti et al. (2016). Our results and similar results in other studies are disturbing because they point to a possibility that some pain interventions may be inadequate, which may increase the risk of chronification (Ranger, Johnston \& Anand 2007; Subhashini, Vatsa \& Lodha 2009).

Interestingly, most participants had good knowledge in the cognitive/behavioural aspect of chronic pain intervention compared with all other domains. This is a non-pharmacological aspect of pain intervention that focuses mainly on the psychological, social and educational aspects. It has been shown to be effective when combined with other modalities (Louw et al. 2016; Turk, Swanson \&
Tunks 2008). Undoubtedly, our study indicates the need to improve clinician's level of knowledge, attitudes and practices to reduce the burden associated with chronic pain. A similar view has been expressed by Goldberg \& McGee 2011; Salazar et al. 2016; Sessle 2012; Stewart et al. 2003. Furthermore, educational intervention particularly continuous medical education and adopting chronic pain guidelines have been recommended to improve clinician's knowledge, attitudes and practices (Gustafsson \& Borglin 2013; Mcnamara, Harmon \& Saunders 2012). Our results form a baseline for further research in a wider population and may inform future review of healthcare policy, training curricula and practices in healthcare in our environment.

\section{Strengths and limitations}

Our study had a good response rate of $83.5 \%(n-=153)$ but was limited by uneven distribution of participants in the different cadres, those with small population may not be sufficient to generalise the results to the larger population.

\section{Implications and recommendations}

We recommend studies to be conducted in a wider population to allow generalisation of the results educating clinicians on the assessment and management of patients with chronic pain, may help in improving their practices. Furthermore, training curricula for all levels of clinicians should emphasise chronic pain management to equip them with appropriate knowledge and skills necessary to assess and manage chronic pain.

\section{Conclusion}

Patients with chronic pain continue to suffer because of clinicians' inadequate knowledge, unhelpful attitudes and generally poor practice. Educating clinicians on best practice about assessment and management of chronic pain and encouraging self-initiated continuing medical education is critical. Our results suggest improvements in education curricula and the quality of healthcare in the region.

\section{Acknowledgements}

The authors would like to thank all clinicians at Tenwek Hospital who volunteered to participate in the study, the members of the Ethics and Review Committee of Jomo Kenyatta University of Agriculture and Technology, Tenwek Hospital and the National Commission for Science and Innovation for their support during this study.

\section{Competing interests}

The authors declare that they have no financial or personal relationships that may have inappropriately influenced them in writing this article. 


\section{Authors' contributions}

S.R. was responsible for development of study protocol, designed the methods, data collection and wrote the manuscript. The co-authors, J.M.M. and N.T. provided validation, supervision for the study protocol and reviewed the manuscript.

\section{Funding information}

This research received no specific grant from any funding agency in the public, commercial or not-for-profit sector.

\section{Data availability}

Data that support this study will be made available by the corresponding author (S.R.) upon reasonable request.

\section{Disclaimer}

The views and opinions expressed in this article are those of the authors and do not necessarily reflect the official policy or position of any affiliated agency of the authors.

\section{References}

Ajay, S. \& Micah, M., 2014, 'Sampling techniques \& determination of sample size in applied statistics research: An overview', International Journal of Economics, Commerce and Management, /I 20(11), 22.

Al-Quliti, K.W. \& Alamri, M.S., 2015, 'Knowledge, attitudes, and practices of health care providers in Almadinah Almunawwarah, Saudi Arabia', Neurosciences 20(2), 131-136. https://doi.org/10.17712/nsj.2015.2.20140546

Bevers, K., Watts, L.F. \& Gatchel, R., 2016, 'The biopsychosocial model of the assessment, prevention, and treatment of chronic pain', US Neurology 12(2), 98-104. https://doi.org/10.17925/USN.2016.12.02.98

Bouri, F., Ansar, W.E., Mahmoud, S., Elhessy, A., Al-Ansari, A. \& Al- Dosari, A.M., 2018 'Orthopedic professionals' recognition and knowledge of pain and perceived barriers to optimal pain management at five hospitals', Healthcare 6(3), 98. https://doi.org/10.3390/healthcare6030098

Breivik, H., Collett, B., Ventafridda,V., Cohen, R. \& Gallacher, D., 2006, 'Survey of chronic pain in Europe: Prevalence, impact on daily life, and treatment', European Journal of Pain 10(4), 287-333. https://doi.org/10.1016/j.ejpain.2005.06.009

Clenzos, N., Naidoo, N. \& Parker, R., 2016, 'Physiotherapists' knowledge of pain: A cross-sectional correlational study of members of the South African Sports and Orthopaedic Manipulative Special Interest Groups', South African Journal of Sports Medicine 25(4), 95. https://doi.org/10.17159/2413-3108/2013/v25i4a337

Duke, G., Barbara, K.H., Yarbrough, S., \& Northam, S., 2013, 'Pain management knowledge and attitudes of baccalaureate nursing students and faculty', Pain Management Nursing 14(1), 11-19. https://doi.org/10.1016/j.pmn.2010.03.006

Enskär, K., Eaton, N. \& Harding, R., 2007, 'Attitudes to and knowledge management, of nurses working with children with cancer: A comparative study between UK', Journal of Research in Nursing 12(5), 501-515. https://doi. org/10.1177/1744987107080455

Ernstzen, D.V., Louw, Q.A. \& Hillier, S.L., 2017, 'Clinical practice guidelines for the management of chronic musculoskeletal pain in primary healthcare: A systematic review', Implementation Science 12(1), 1-13. https://doi.org/10.1186/s13012 016-0533-0

Espejo-Tort, B., Segura-Orti, E., Domenech, J., Lison, J.F., Sanchez-Zuriaga, D., 2011, 'Impact of biomedical and biopsychosocial training sessions on the attitudes, beliefs, and recommendations of health care providers about low back pain: A randomised clinical trial', Pain 152(11), 2557-2563. https://doi.org/10.1016/j pain.2011.07.023

Ferrell, B.R. \& McCaffery, M., 2012, 'Knowledge and attitudes survey regarding pain', Journal of Palliative Medicine 207-214. https://doi.org/10.13072/midss.341

Goldberg, D.S. \& McGee, S.J., 2011, 'Pain as a global public health priority', BMC Public Health 11, 770. https://doi.org/10.1186/1471-2458-11-770

Gustafsson, M. \& Borglin, G., 2013, 'Can a theory-based educational intervention change nurses' knowledge and attitudes concerning cancer pain management? A quasi-experimental design', BMC Health Services Researche 13(328), 1472-6963. https://doi.org/10.1186/1472-6963-13-328
International Association for the Study of Pain, 2015, What is neuropathic pain?, pp. 1-3, International Association for the Study of Pain, Washington, DC. https:// doi.org/10.1053/j.gastro.2015.12.037

Jin, Z., 2015, 'Knowledge and attitude of health care workers at Kenyatta National Hospital on pain assessment and management in children', PhD thesis, University of Nairobi.

Kheshti, R., Namazi, S., Mehrabi, M. \& Firohzabadi, D., 2016, 'Health care workers' knowledge, attitude, and practice about chronic pain management, Shiraz, Iran' Anesthesiology and Pain Medicine 6(4), e37270. https://doi.org/10.5812/ aapm. 37270

Kiwanuka, F. \& Masaba, R., 2018, 'Nurses' knowledge, attitude and practices regarding pain assessment among patients with cancer at Uganda Cancer Institute', Journa of Analytical Research in Clinical Medicine 6(2), 72-79. https://doi.org/10.15171/ jarcm.2018.011

Kizza, I.B., Mulira, J.K., Kohil, T.W. \& Nabirye, R.C., 2016, 'Nurses' knowledge of the principles of acute pain assessment in critically ill adult patients who are able to self-report', International Journal of Africa Nursing Sciences 4, 20-27. https://doi. org/10.1016/j.ijans.2016.02.001

Louw, A., Zimney, K., Puentedura, E.J. \& Diener, I., 2016, 'The clinical application of teaching people about pain', Physiotherapy Theory and Practice 32(5), 385-395. https://doi.org/10.1080/09593985.2016.1194652

Magalhães, M.O., Leonardo, O.P.C., Cristina, M.N.C. \& Luciana, A.C.M., 2012, 'Attitudes and beliefs of Brazilian physical therapists about chronic low back pain: A crosssectional study', Brazilian Journal of Physical Therapy 16(3), 248-253. https://doi. org/10.1590/s1413-35552012005000014

Mcnamara, M.C., Harmon, D. \& Saunders, J., 2012, 'Effect of education on knowledge, skills and attitudes around pain', British Journal of Nursing 21(16), 958, 960-964. https://doi.org/10.12968/bjon.2012.21.16.958

Miró, J., Elena, C., Ester, S., Isabel, S. \& Francisco, R.B., 2019, 'Pain curricula across healthcare professions undergraduate degrees: A cross-sectional study in Catalonia, Spain', BMC Medical Education 19(1), 1-8. https://doi.org/10.1186/ catalonia, Spain', BMC

Moseley, G.L., 2008, 'Reconceptualising pain according to modern pain science', Physical Therapy Reviews 12(3), 169-178. https://doi.org/10.1179/ $108331907 \times 223010$

Nuseir, K., Kassab, M. \& Almomani, B., 2016, 'Healthcare providers' knowledge and current practice of pain assessment and management: How much progress have we made?', Pain Research and Management 2016, 1-7. https://doi. org/10.1155/2016/8432973

Raja, S.N., Daniel, C.B., Cohen, M., Finnerup, N.B., Flor H. \& Stephen, G., 2020, 'The revised IASP definition of pain:concepts, challenges, and compromises', Pain 161(9), 1976-1982. https://doi.org/10.1097/j.pain.0000000000001939

Ranger, M., Johnston, C.C. \& Anand, K.J.S., 2007, 'Current controversies regarding pain assessment in neonates', Seminars in Perinatology 31(5), 283-288. https://doi org/10.1053/j.semperi.2007.07.003

Ryan, C., Dervla, M., Micheal, C. \& Andrew, L., 2010, 'The effect of a physiotherapy education compared with a non-healthcare education on the attitudes and beliefs of students towards functioning in individuals with back pain: An observational cross-sectional study', Physiotherapy 96(2), 144-150. https://doi.org/10.1016/j. physio.2009.09.010

Salazar, A., Mico, J.A. \& Failde, I., 2016, 'A review of chronic pain impact on patients, their social environment and the health care system', Journal of Pain Research 9 457-467. https://doi.org/10.2147/JPR.s105892

Sessle, B.J., 2012, 'The pain crisis: What it is and what can be done', Pain Research and Treatment 2012, 1-6. https://doi.org/10.1155/2012/703947

Shipton, E.E., Frank, B., Raymond, G., Carole, S., Edward A.S. \& Eric, J.V., 2018, 'Systematic review of pain medicine content, teaching, and assessment in medical school curricula internationally', Pain and Therapy 7(2), 139-161. https://doi. org/10.1007/s40122-018-0103-z

Stewart, W.F., Judith, A.R., Elsbeth, C., David, M. \& Richard, L., 2003, 'Lost productive time and cost due to common pain conditions in the US workforce', Journal of the American Medical Association 290(18), 2443-2454. https://doi.org/10.1001/ jama.290.18.2443

Subhashini, L., Vatsa, M. \& Lodha, R., 2009, 'Knowledge, attitude and practices among health care professionals regarding pain', Indian Journal of Pediatrics 76(9), 913-916. https://doi.org/10.1007/s12098-009-0154-6

Treede, R., Milton, C., John, Q. \& Van, S.R., 2018, 'The International Association for the Study of Pain definition of pain: As valid in 2018 as in 1979, but in need of regularly updated footnotes', Pain Reports 3(2), e643. https://doi. org/10.1097/PR9.0000000000000643

Turk, D.C., Swanson, K.S. \& Tunks, E.R., 2008, 'Psychological approaches in the treatment of chronic pain patients-when pills, scalpels, and needles are not enough', Canadian Journal of Psychiatry 53(4), 213-223. https://doi. org/10.1177/070674370805300402

Ung, A., Yenna, S., Wendy, S. \& Gisselle, G., 2016, 'Assessing knowledge, perceptions and attitudes to pain management among medical and nursing students: A review of the literature', British Journal of Pain 10(1), 8-21. https://doi org/10.1177/2049463715583142

Yaqoob, S.H. \& Nasaif, H.A., 2015, 'Nurses' knowledge and attitudes toward pain assessment and management for adult sickle cell disease patients during sickling crisis', Clinical Nursing Studies 3(4), 36. https://doi.org/10.5430/cns.v3n4p36 